\title{
Residual stresses in 18CrNiMo7-6 linear friction welded high strength steel chains
}

\author{
D. G. Nunes ${ }^{1} \cdot$ P. S. Effertz ${ }^{2} \cdot$ L. Quintino ${ }^{1} \cdot$ I. Pires $^{1} \cdot$ F. Fuchs $^{3} \cdot$ N. Enzinger ${ }^{2}$
}

Received: 28 December 2017 / Accepted: 1 March 2018

(C) Springer-Verlag London Ltd., part of Springer Nature 2018

\begin{abstract}
Linear friction welding is a solid-state process that comprises rapid heating and cooling of the welded parts. Residual stresses (RS) as in every other welding process cannot be avoided. The presence of RS compromises the in-service performance and reliability. They influence stress corrosion cracking, fatigue strength, and the crack growth rate. Knowing the magnitude and nature of such stresses is critical for improving the quality of welded joints. Therefore, four different manufacturing stages of linear friction welded chain links were analyzed in the present study: "as forged" $(F)$, "as welded" $(A)$, "as welded" without flash $(N)$, and post weld heat treated $(P)$. The residual stress field was measured using the hole drilling (HD) method. The results of the hole drilling method showed to be independent of the measured position and symmetry with respect to the weld was observed in all evaluated regions. Close to the weld center line (WCL), the compressive stresses present in the "as forged" condition switched to tensile as a result of the welding process. However, in further regions, stresses remained almost unchanged for either $A$ and $N$. The PWHT uniformizes the residual stress field along the whole weld region.
\end{abstract}

Keywords Residual stresses $\cdot$ Chain links $\cdot$ Hole drilling $\cdot$ X-ray diffraction $\cdot$ Linear friction welding

\section{Introduction}

Linear friction welding (LFW) is a process where friction is created through linear reciprocating movement of a part. After the material is heated, a compressive (forging) force which joins both components is applied [1-6]. Material in the form of a flash is expelled from the weld interface due to the reciprocate movement of the part [7]. Due to all the advantages of the process, LFW implementation in the manufacturing of steel chains has been thoroughly

\section{G. Nunes}

dinis.nunes@tecnico.ulisboa.pt

1 IDMEC, Instituto Superior Técnico, Universidade de Lisboa, Av. Rovisco Pais, 1049-001 Lisbon, Portugal

2 Institute of Materials Science and Welding, Graz University of Technology, Kopernikusgasse 24/I, 8010 Graz, Austria

3 pewag austria $\mathrm{GmbH}$, Mariazeller Straße 143, 8605 Kapfenberg, Austria investigated in the past years. The present work extends the knowledge on the topic by studying the RS field in steel chains joined using LFW.

Hole drilling is a semi-destructive method, relatively fast to apply and provides reliable results close to the surface of the structure of interest. A small hole is drilled on the specimen with a cylindrical end-mill, and the deformation on the surface is measured using a strain gauge rosette [8-12]. With this value, it is possible to calculate the stresses released in the specimen that are commonly biaxial $[13,14]$. Stefanescu et al. [15] investigated the RS state in an aluminum alloy using HD and reported that it is possible to obtain reliable results until 1-mm depth of the hole.

The novelty in this article is presenting a quantitative measurement of the residual stress field in LFW 18CrNiMo7-6 steel chains, considering the welding parameters and the flash formation are already studied in detail [16]. The RS field was evaluated using HD technique. Not only in the as forged initial condition (F), but also in the as welded condition (A), so the influence of the process in the residual stress field is characterized. 
Tests were also performed to study how this stress field is influenced by the removal of the flash $(\mathrm{N})$ and, furthermore, analyze the consequences of performing a PWHT (P).

\section{Experimental procedure-methodology}

\subsection{Materials and test coupons}

The alloy used in this investigation is martensitic 18CrNiMo7-6 steel. The chemical composition in weight percent and the mechanical properties at room temperature are shown in Tables 1 and 2, respectively.

The test coupons used were half chain links with the following dimensions: $77 \mathrm{~mm}$ length, $83 \mathrm{~mm}$ of width and a cross section of $22 \mathrm{~mm}$ of width and $24 \mathrm{~mm}$ of height as shown in Fig. 1. The directions $x, y$, and $z$ correlate with the directions of reciprocating movement, forging force and perpendicular to the reciprocating movement, respectively.

\subsection{Welding}

The welds were performed using a prototype linear friction welding machine at pewag Austria GmbH. The half links are firmly clamped in the machine. The apparatus consists of two actuators: the in-plane actuator responsible for the oscillating movement of the moving (M) part in the x-direction; and forge actuator that applies the axial load in the y-direction on the stationary (S) part. Optimized welding parameters were used for all samples [17].

\subsection{Hole drilling method}

This test was performed using a SINT MTS 3000 drilling system according to the ASTM E837 standard. This system consists of four main components: a mechanical driller, powered by an air turbine, with an assembled step motor, an electronic controller, operating software for the driller, and a post-processing software to calculate the stresses through the measured strains. The drilled holes have $1.6 \mathrm{~mm}$ diameter and a final depth of $1.5 \mathrm{~mm}$. The strain gauge rosettes used were the circular HBM RY61S $\left(0^{\circ} / 45^{\circ} / 90^{\circ}\right)$ and the rectangular HBM RY61K $\left(0^{\circ} / 45^{\circ} / 90^{\circ}\right)$.

Table 1 Chemical composition of 18CrNiMo7-6 (wt $\%$ )

\begin{tabular}{llllllll}
\hline $\mathrm{C}$ & $\mathrm{Si}$ & $\mathrm{Mn}$ & $\mathrm{Ni}$ & $\mathrm{P}$ & $\mathrm{S}$ & $\mathrm{Cr}$ & $\mathrm{Mo}$ \\
\hline 0.18 & 0.27 & 0.58 & 1.62 & 0.011 & 0.008 & 1.76 & 0.250 \\
\hline
\end{tabular}

Table 2 Mechanical properties of $18 \mathrm{CrNiMo} 7-6$ at room temperature

\begin{tabular}{llll}
\hline $\begin{array}{l}\text { Young modulus } \\
(\mathrm{GPa})\end{array}$ & $\begin{array}{l}\text { Yield strength } \\
(\mathrm{MPa})\end{array}$ & $\begin{array}{l}\text { Tensile strength } \\
(\mathrm{MPa})\end{array}$ & $\begin{array}{l}\text { Elongation } \\
(\%)\end{array}$ \\
\hline 210 & 785 & 1080 & 8 \\
\hline
\end{tabular}

The hole drilling technique involves precision equipment. Hence, a careful preparation of the test coupons is required as well as a great expertise in handling the devices aforementioned. The surface where the strain gauge rosette was applied should be completely flat. Therefore, the measurement regions were grinded using a 320- $\mu \mathrm{m}$ paper. Afterwards, the grinded surface was cleaned with a solution of aceton+isopropanol to remove any impurities that could remain between the sample and the strain gauge rosette. The solution used was a HBM RMS1. The strain gauge rosette was glued to the sample using a cyanoacrylate HBM Z70 glue. After the rosette is glued to the specimen, the data acquisition cables were soldered using a standard soldering tool. A HBM FS01 flux was applied before soldering to avoid introduction of impurities. The application of the rosette as well as the soldering process may introduce strains that should not be accounted in the measurement. Thus, after soldering, the software was tared to make all the strains measured as zero.

The software used allows the calculation of the principal stresses using the deformation values measured. Through these values, it was possible to compute the stresses in the direction of the weld $\sigma_{\mathrm{x}}$ and transversely to it $\sigma_{\mathrm{y}}$. The calculation method used was the Kockelmann's method, which relies on calibration functions, given in Eqs. 1 and 2. These functions can be obtained for all the strain gauge rosettes produced by HBM.

$$
\begin{aligned}
& K_{x}(\xi)=\frac{E}{\sigma} \frac{d \varepsilon_{x}}{d \xi} \\
& K_{y}(\xi)=\frac{E}{\sigma} \frac{d \varepsilon_{y}}{d \xi}
\end{aligned}
$$

where $\xi$ is the relation between the hole depth and the diameter, $E$ the Young Modulus of the material, and $\varepsilon_{x}$ and $\varepsilon_{y}$ are the strains parallel and perpendicular to the reciprocating direction, respectively.

The principal stresses $\sigma_{1,2}(\xi)$ and the orientation angle $\boldsymbol{\alpha}$ can be calculated through Eqs. 3 and 4 respectively.

$$
\begin{aligned}
\sigma_{1,2}(\xi)= & \frac{\sigma_{a}(\xi)+\sigma_{c}(\xi)}{2} \\
& +\frac{1}{\sqrt{2}} \sqrt{\left(\sigma_{a}(\xi)-\sigma_{b}(\xi)\right)^{2}+\left(\sigma_{c}(\xi)-\sigma_{b}(\xi)\right)^{2}} \\
\alpha(\xi)=\frac{1}{\arctan \left(2 \sigma_{b}(\xi)-\sigma_{a}(\xi)-\sigma_{c}(\xi)\right)} & \sigma_{a}(\xi)-\sigma_{c}(\xi)
\end{aligned}
$$


Fig. 1 Technical drawing and isometric view of one half chain link
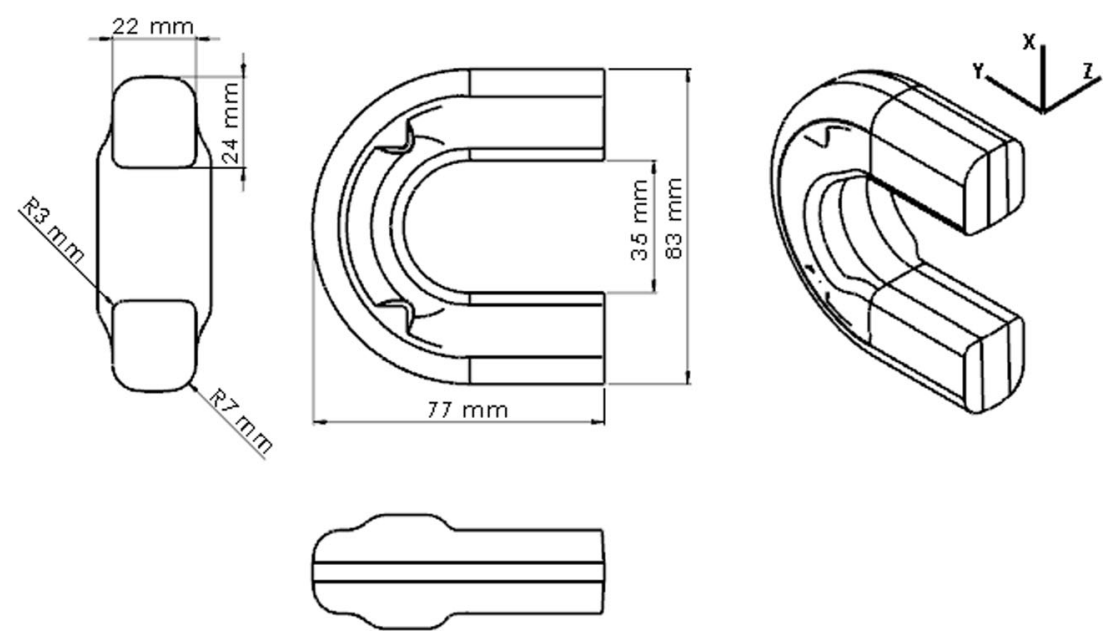

where $\sigma_{a}, \sigma_{b}$, and $\sigma_{c}$ are the stresses in the direction of the strain gauges $\mathrm{a}, \mathrm{b}$, and c respectively. These stresses are obtained using the previously mentioned calibration functions.

Given the geometry of the chains, the clamping of the component was carefully set to reduce vibrations during drilling. After the driller was positioned in the center of the rosette and the zero-reference point was defined (after drilling the rosette's foil surface), the hole was incrementally drilled and the results for each step recorded by the data acquisition system.

Considering the stationary half link as the reference, the measurement locations are defined as shown in Fig. 2. The holes were drilled 3 and $23 \mathrm{~mm}$ away from the WCL.

\section{Results and discussion}

\subsection{Residual stresses in the as forged condition (F)}

The measurements performed in the as forged condition are prior to welding and serve as reference to the initial stress state of the half chain links. The locations where the measurements are performed are depicted in Fig. 3. The measurements were carried out on the TL and LS as shown in Fig. 4a, b, respectively. According to Fig. 4a, the maximum compressive stress values occur in a depth less than $0.2 \mathrm{~mm}$, with -550 and -

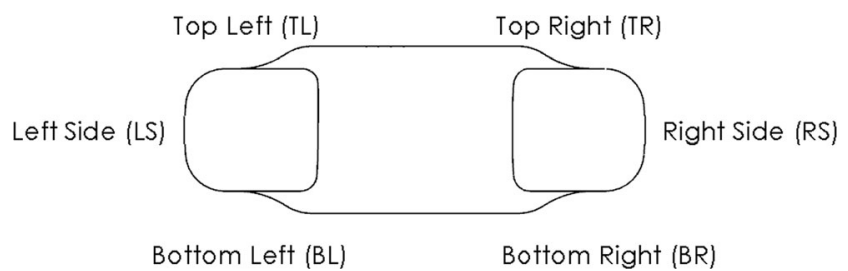

Fig. 2 Locations of the hole drilling measurements-illustration of the moving part
$400 \mathrm{MPa}$ along the $\mathrm{x}$ and $\mathrm{y}$ direction, respectively. The compressive stress values gradually approach zero as the depth increases. This behavior was expected since the samples were submitted to a shot peening treatment after forging, inducing compressive stresses at the surface of the specimen. The RS results obtained are in good agreement with the existing literature for shot-peened specimens $[18,19]$ in which the maximum absolute stress value remains close to the surface of the component and tends to zero further from the surface.

\subsection{Residual stresses in the as welded condition (A)}

\subsubsection{Comparison between $F$ and $A$}

The influence of the welding process in the RS field was evaluated. To that end, conditions $F$ and $A$ were compared, and the measured regions are shown in Fig. 5. The stress field of both $F$ and $A$ conditions $3 \mathrm{~mm}$ from the WCL showed a clear tendency of relaxation in compressive residual stress. $\sigma_{x}$ decreases from a maximum absolute value of around $-400 \mathrm{MPa}$ to approximately $0 \mathrm{MPa}$, as shown in Fig. 6a. This value, $3 \mathrm{~mm}$ away from the WCL in the A condition, increases to a maximum of around $250 \mathrm{MPa}$ when increasing depth. Regions closest to the WCL are subjected to a high thermal cycle during the welding process. However, during cooling, these same regions are the last to reach room temperature again. Thus, close to the WCL the stress state at the surface is tensile $[4,20]$. Far away from the WCL, the difference between the F and A conditions is smaller or even negligible. The switching to tensile stress is not observed $23 \mathrm{~mm}$ away from the WCL. In this region, the material is not subjected to severe thermal cycles, which is the reason why stresses not vary significantly.

In the y direction, a difference of $\sim 200 \mathrm{MPa}$ has been observed $0.1 \mathrm{~mm}$ from the surface, which might be related to the aforementioned measurement errors, or by the 


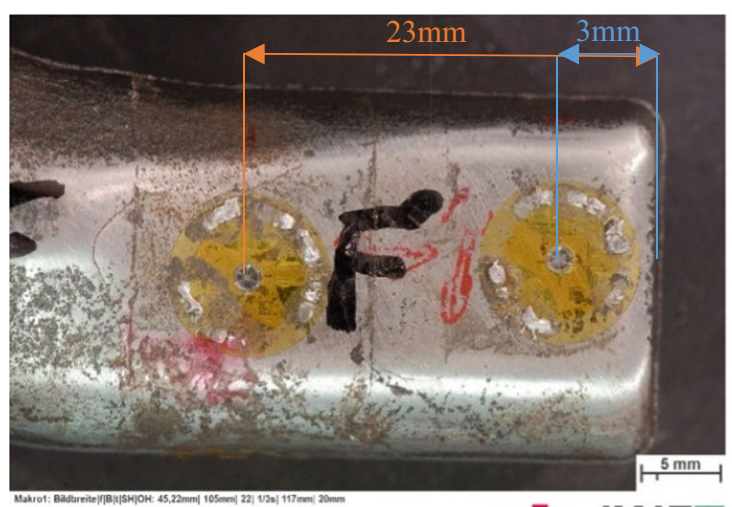

Bildname: joinp3kette17_u0166.jpg

a)

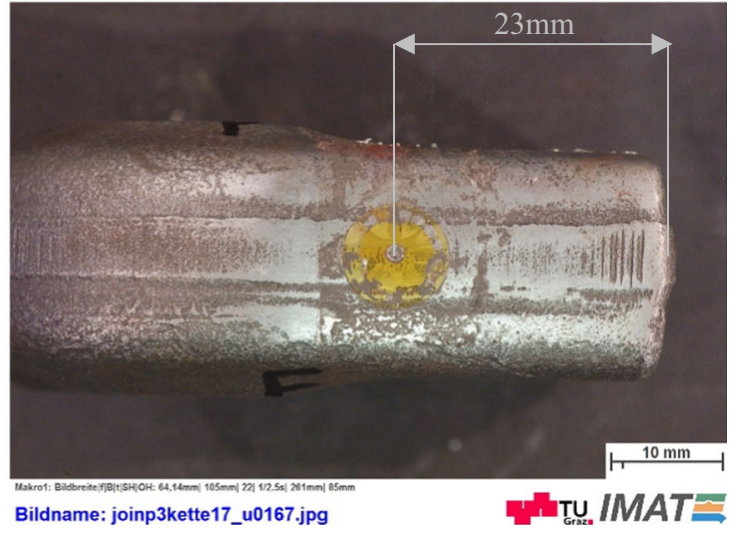

b)

Fig. 3 Location of the measurements in the F condition. a TL region. b LS region

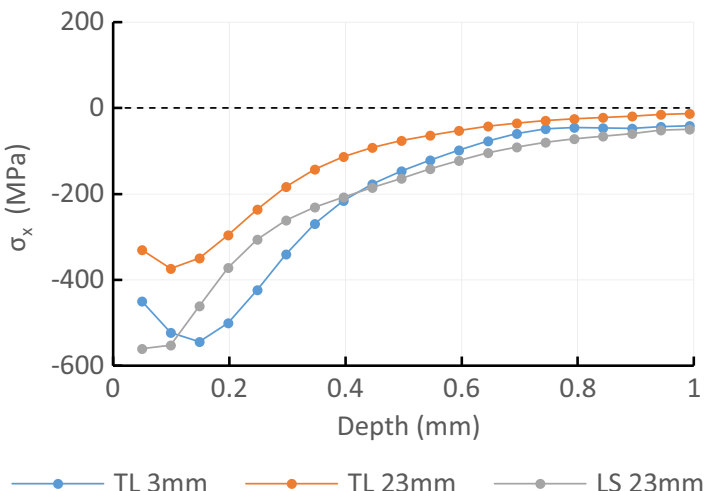

a)

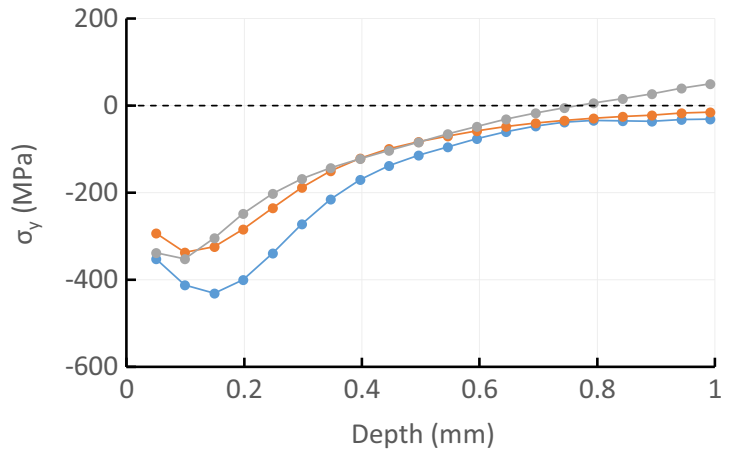

TL 3mm

b)

Fig. 4 Residual stresses $\mathbf{a} \sigma_{x}, \mathbf{b} \sigma_{y}$ in three different locations of the as forged samples

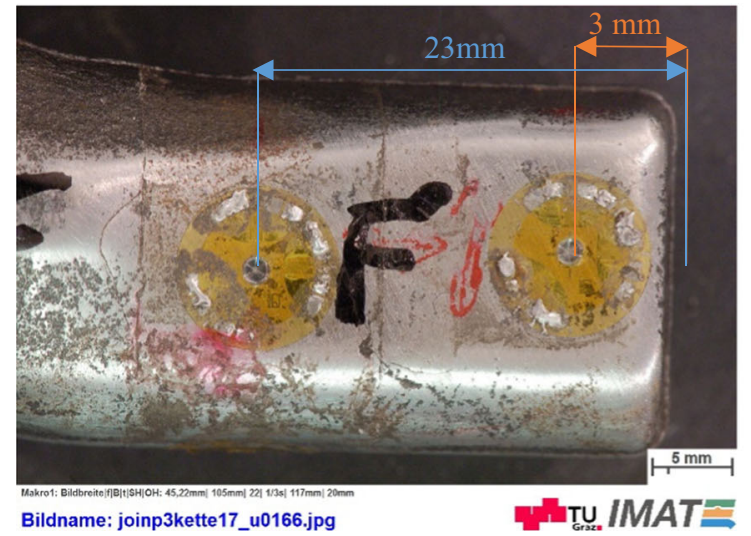

a)

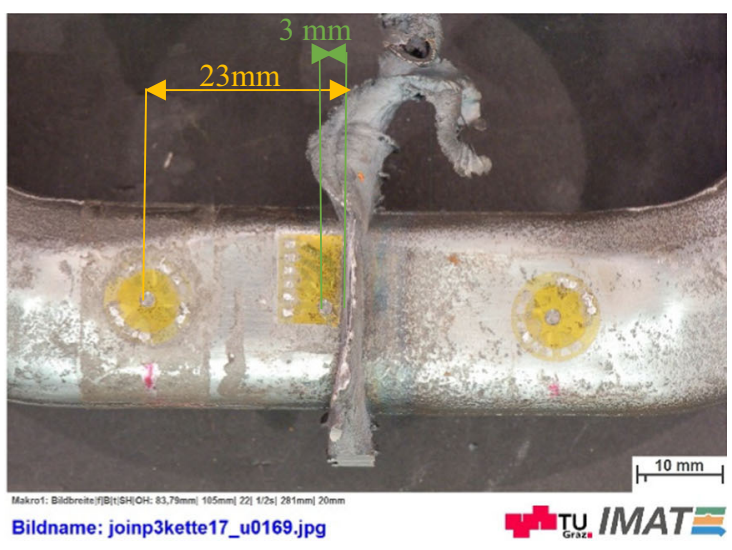

b)

Fig. 5 Location of the measurements in the $\mathbf{a} \mathrm{F}$ and $\mathbf{b}$ A conditions. TL $3 \mathrm{~mm}$ and $23 \mathrm{~mm}$ regions 


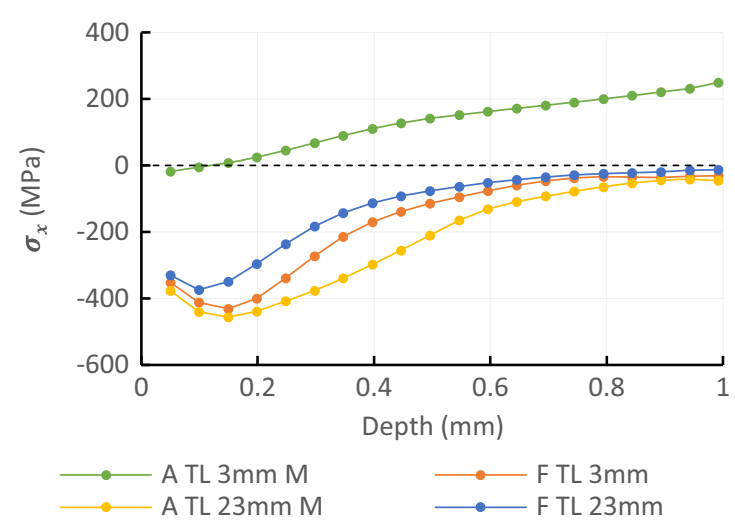

a)

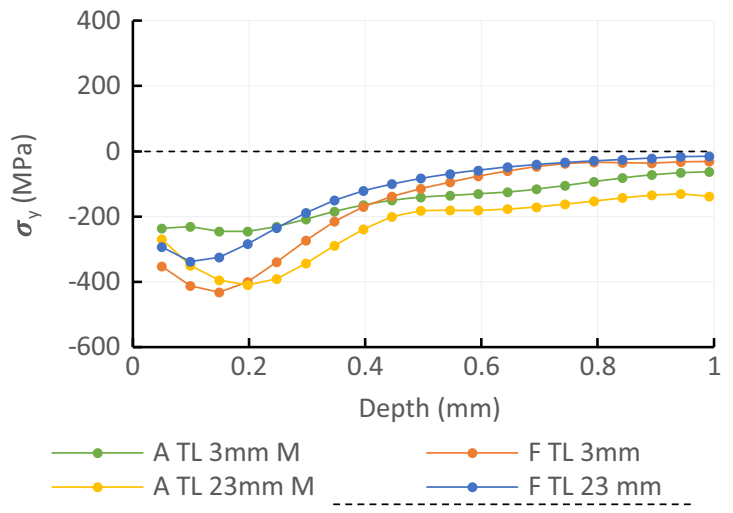

b)

Fig. 6 Residual stresses $\mathbf{a} \sigma_{x}, \mathbf{b} \sigma_{y} 3$ and $23 \mathrm{~mm}$ away from the weld line

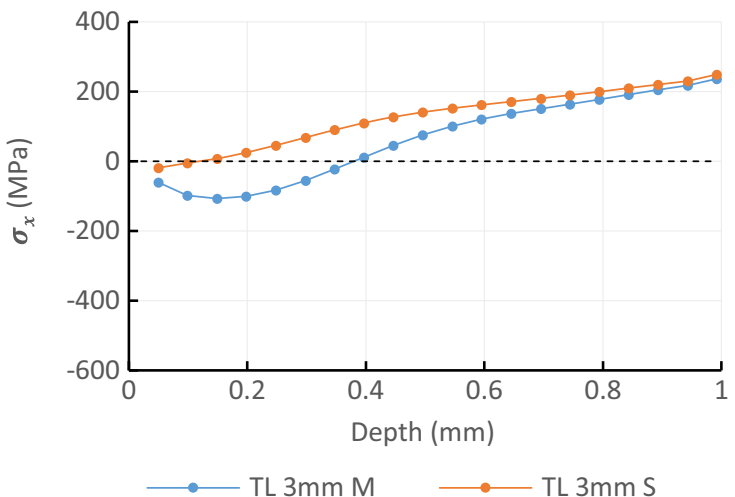

a)

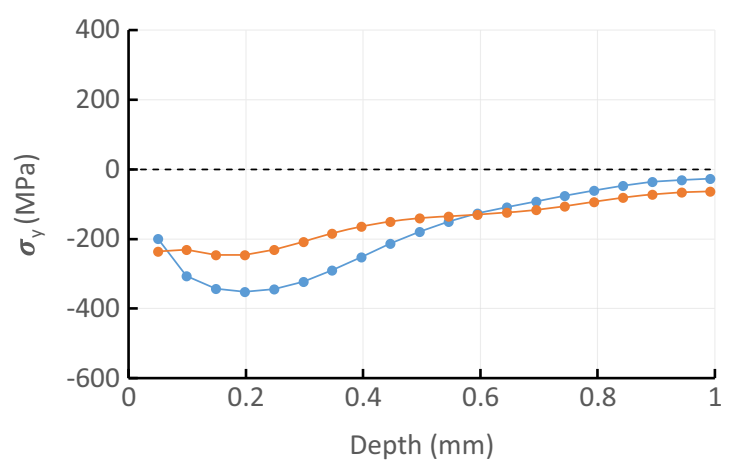

b)

Fig. 7 Residual stresses $\mathbf{a} \sigma_{x}, \mathbf{b} \sigma_{y} 3 \mathrm{~mm}$ away from the weld line in $\mathrm{M}$ and $\mathrm{S}$ parts

variations in the temperature gradient at the surface of the chain after shot peening was applied. However, both conditions exhibit the same residual stress from $0.3 \mathrm{~mm}$ onwards. This can be attributed to fact that it corresponds to the direction of the forging load. When investigating the residual stresses in titanium Turner et al. [21] and Frankel et al. [22] observed a similar trend. In this direction, $3 \mathrm{~mm}$ away from $\mathrm{WCL}$, the maximum compressive value reaches $\sim 250 \mathrm{MPa}$

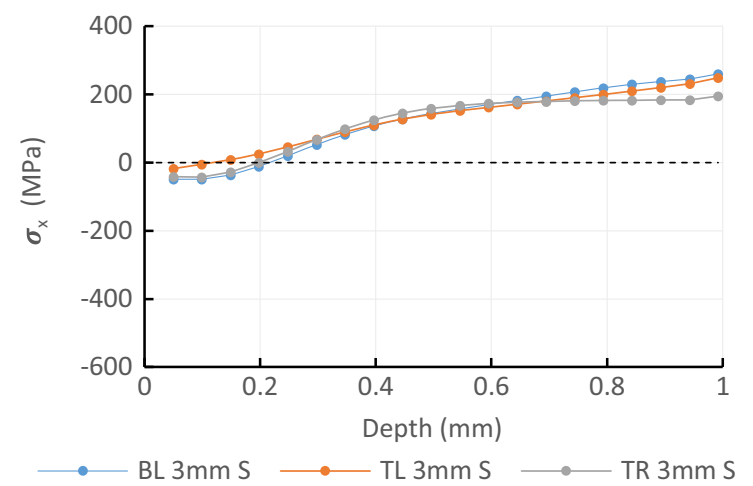

a)

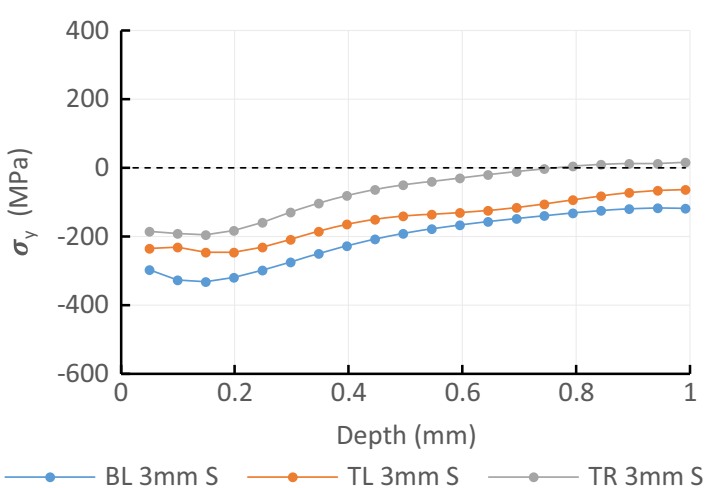

b)

Fig. 8 Residual stresses $\mathbf{a} \sigma_{x}, \mathbf{b} \sigma_{y} 3 \mathrm{~mm}$ away from the weld line in TL, BL, and TR 


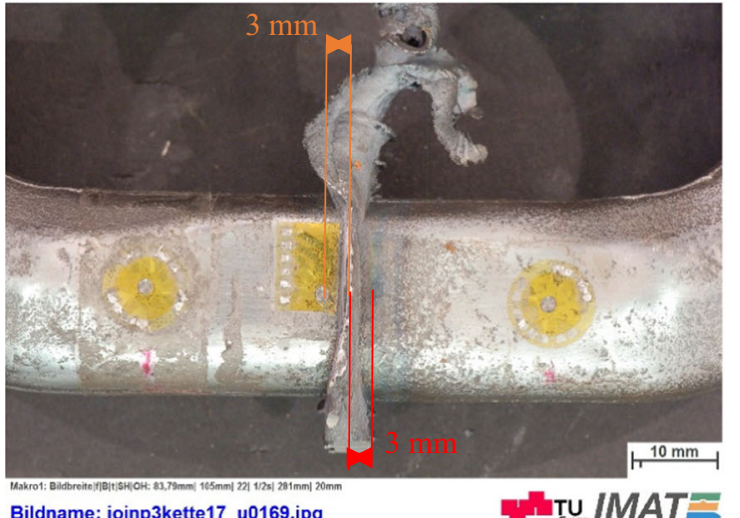

a)

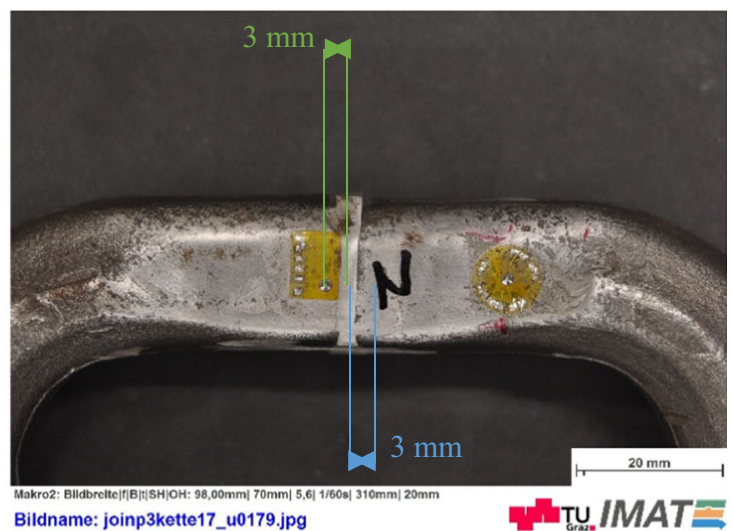

b)

Fig. 9 Location of the measurements in the $\mathbf{a} \mathrm{A}$ and $\mathbf{b} \mathrm{N}$ conditions. TL $3 \mathrm{~mm}$ region

against $\sim 420 \mathrm{MPa}$ obtained $23 \mathrm{~mm}$ away from it. Although as the depth increases, this difference tends to the typically obtained in $\mathrm{HD}$ of $\sim 100 \mathrm{MPa}$.

Far away from the weld center line, both the transverse and parallel residual stresses show a variation of less than $100 \mathrm{MPa}$. It was confirmed that $23 \mathrm{~mm}$ away from the WCL, the RS field does not change since it is far away from the HAZ. In this region, the material is not affected neither by the thermic nor the plastic deformation cycles. Therefore, no significant differences were observed even after the welding procedure.

\subsubsection{Comparison between stationary and moving}

A comparative analysis regarding $\mathrm{S}$ and $\mathrm{M}$ parts of the welded links was carried out. Figure 7a depicts the general tensile nature of the $\sigma_{x}$ close to the WCL, with a peak stress of $\sim 250 \mathrm{MPa}$. Considering the typical error

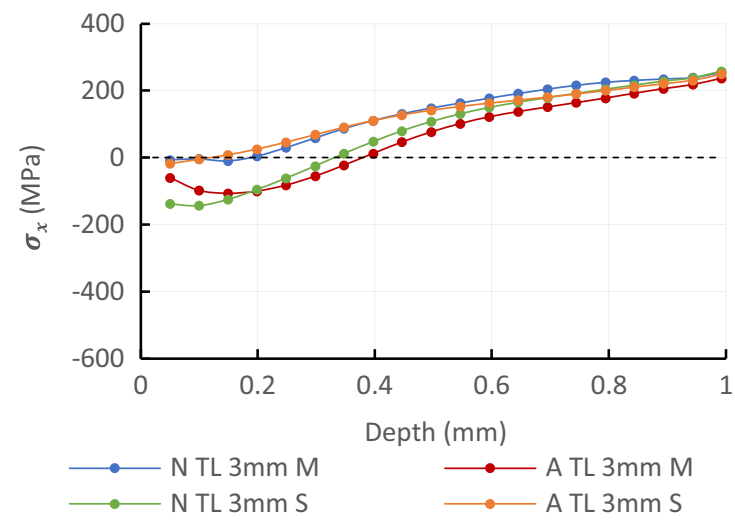

a) obtained in this methodology, the RS field might be considered qualitatively equal.

Regarding $\sigma_{y}$, the same similar behavior was obtained when comparing $\mathrm{S}$ with $\mathrm{M}$. The switch from a compressive to a tensile stress state was not verified in this direction as in $\mathrm{x}$.

\subsubsection{Symmetry of the RS field}

To evaluate the symmetry of the residual stress field between the top/bottom locations and left/right areas of the chain link, measurements were performed at an exact same distance of the WCL. In Fig. 8a, it can be observed that the RS field is almost the same when comparing top left and bottom left of the chain link along the whole depth of the hole. The same for top left and top right.

Regarding the stresses in y direction (Fig. 8b), there is a constant difference of around $100 \mathrm{MPa}$. This difference might be explained by common measurement errors in

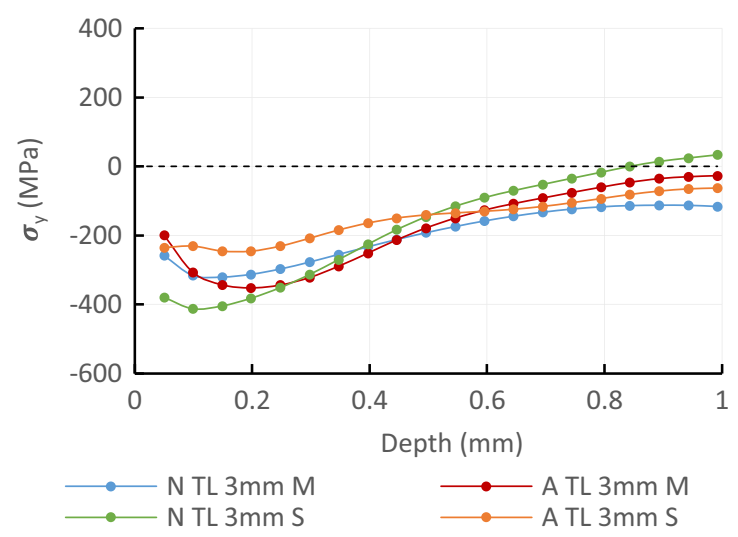

b)

Fig. 10 Residual stresses $\mathbf{a} \sigma_{x}, \mathbf{b} \sigma_{y} 3 \mathrm{~mm}$ away from the weld line in A and $\mathrm{N}$ conditions 


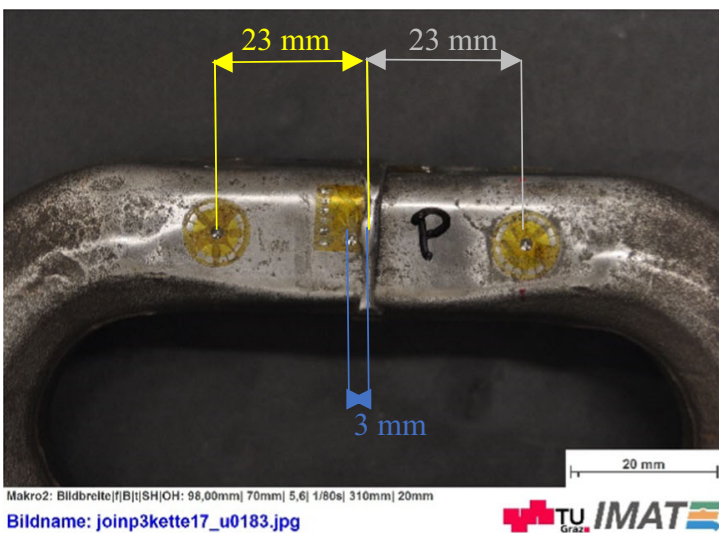

a)

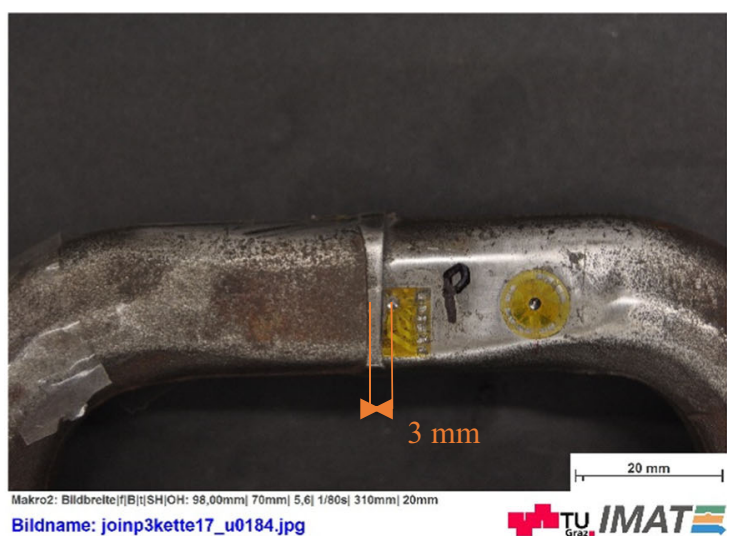

b)

Fig. 11 Residual stresses a $\sigma_{x}, \mathbf{b} \sigma_{y} 3 \mathrm{~mm}$ away from the weld line in the P condition

hole drilling such as not drilling the hole in the exact same point in each location or misplacements of the strain gauge.

\subsection{Residual stresses in the as welded condition after removing the flash $(\mathrm{N})$}

The influence of the flash cutting in the RS fields was assessed as described in Figure 9. The flash was removed mechanically in cold condition Figure 10 shows the results obtained for the $\mathrm{TL}$ region $3 \mathrm{~mm}$ from the WCL, comparing them to the A condition. Although, the removal of the flash would cause differences in the local RS field, due to the geometry of the surface, direct measurements in the WCL were not possible. Nonetheless, for the measured positions $3 \mathrm{~mm}$ away from the WCL, no significant differences derived from the flash removal.

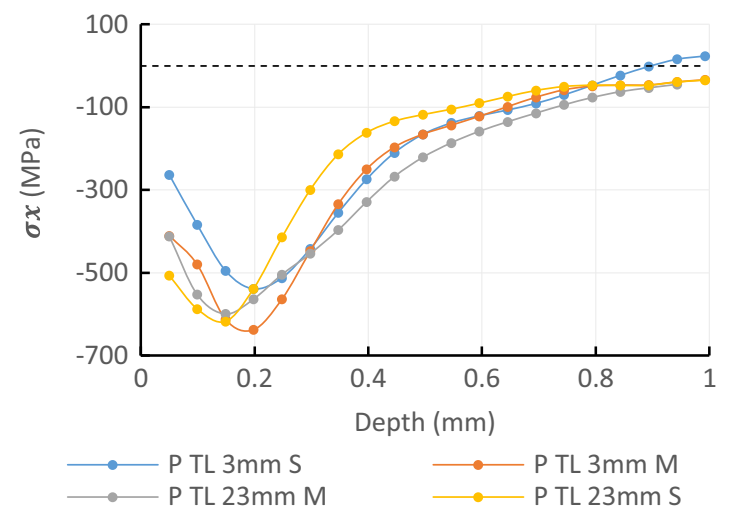

a)

\subsection{Residual stresses in the as welded condition after removing the flash (N) and after PWHT (P)}

To evaluate the effects of PWHT, the same tests were performed as before in a heat-treated condition after removing the flash. The location where the measurements were performed is shown in Fig. 11. The PWHT operation consists of heating the component in a salt bath at $830{ }^{\circ} \mathrm{C}$ for $20 \mathrm{~min}$, quenching at $180^{\circ} \mathrm{C}$ for $5 \mathrm{~min}$ and annealing for $1 \mathrm{~h}$ at $500{ }^{\circ} \mathrm{C}$.

These results, depicted in Fig. 12, show that the annealing in these conditions influences mostly the regions close to the surface of the specimen. The tensile RS present due to the joining process switched back to compressive due to the PWHT. This can be explained since the steel was heated above its austenitization temperature. The values obtained were slightly higher than the obtained in other conditions. Due to the PWHT after welding and flash removing, the RS

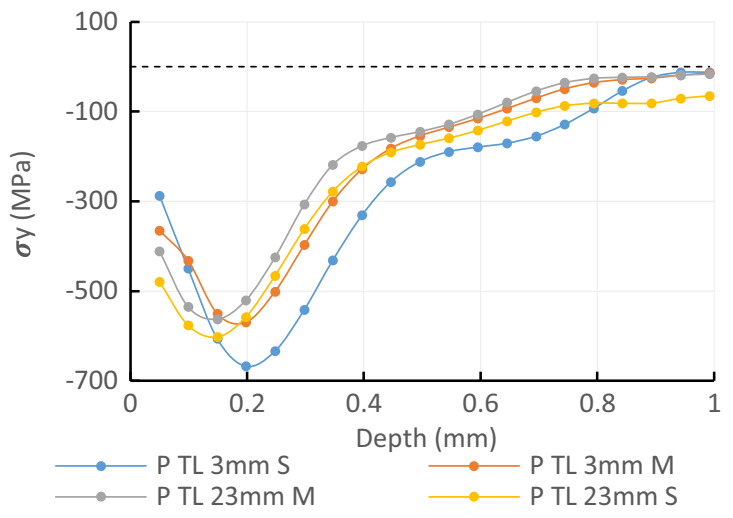

b)

Fig. 12 Residual stresses $\mathbf{a} \sigma_{x}, \mathbf{b} \sigma_{y} 3 \mathrm{~mm}$ away from the weld line in $\mathrm{P}$ condition 
history that was present in the sample is replaced by a completely new and homogeneous stress field.

\section{Conclusions}

The present work intended to describe the evolution of the RS state throughout the main manufacturing stages of 18CrNiMo7-6 linear friction welded steel chains using the hole drilling method:

1. After forging the components $(\mathrm{F})$ showed the typical stress distribution of shot peened part.

2. It was shown that close to the WCL, in the direction of the reciprocating movement $(\mathrm{x})$, the compressive stresses present in the F condition switch into tensile due to the LFW procedure. In the direction of the forging force (y), the stresses remained compressive after the LFW process. In the forge direction, the shot peening stresses remained conserved.

3. It was observed symmetry of the residual stress field between the TL/TR and TL/BL locations. There is a small increase of the compressive stresses regarding the moving (M) component when compared to the stationary (S) one. Away from the WCL, no difference between $\mathrm{M}$ and $\mathrm{S}$ parts was observed.

4. The flash removal process does not have influence in the residual stress field close to the WCL.

5. The applied PWHT switches the tensile stresses due to the welding process back into compressive. In this condition, higher values of compressive stresses close to the surface of the specimen were reached than any of the other conditions studied.

Acknowledgements The authors gratefully acknowledge the financial support of this work by the project JOIN. The K-Project Network of Excellence for Joining Technologies JOIN is fostered in the frame of COMET - Competence Centers for Excellent Technologies by BMVIT, BMWFJ, FFG, Land Oberöstereich, Land Steiermark, SFG, and ZIT. The program COMET is handled by FFG.

\section{References}

1. Funderburk S (1986) Postweld heat treatments, pergamon press Ltd., Encycl. Mater ..., vol. XV, no. 2

2. McAndrew AR, Colegrove PA, Flipo BCD, Bühr C (2016) 3D modelling of Ti-6Al-4V linear friction welds. Sci Technol Weld Join., vol. XXII. (December) p 1-9
3. Bhamji I, Preuss M, Threadgill PL, Moat RJ, Addison AC, Peel MJ (2010) Linear friction welding of AISI 316L stainless steel. Mater Sci Eng A 528(2):680-690

4. Smith M, Levesque J-B, Bichler L, Sediako D, Gholipour J, Wanjara P (2017) Residual stress analysis in linear friction welded in-service Inconel 718 superalloy via neutron diffraction and contour method approaches. Mater Sci Eng A 691(February):168-179

5. Vairis A (2012) Mathematical modelling of the linear friction welding process. J Eng Sci Technol Rev 5(3):25-31

6. Li WY, Ma TJ, Yang SQ, Xu QZ, Zhang Y, Li JL, Liao HL (2008) Effect of friction time on flash shape and axial shortening of linear friction welded 45 steel. Mater Lett 62(2):293-296

7. Bhamji I, Preuss M, Threadgill PL, Addison AC (2011) Solid state joining of metals by linear friction welding: a literature review. Mater Sci Technol 27(1):2-12

8. Schajer GS (2010) Advances in hole-drilling residual stress measurements. Exp Mech 50(2):159-168

9. Schajer GS (2009) Hole-drilling residual stress measurements at 75: origins, advances, opportunities, Exp Mech, vol. L

10. Rendler NJ, Vigness I (1966) Hole-drilling strain-gage method of measuring residual stresses. Exp Mech 6(12):577-586

11. Rossini NS, Dassisti M, Benyounis KY, Olabi AG (2012) Methods of measuring residual stresses in components. Mater Des 35:572588

12. Barile C, Casavola C, Pappalettera G, Pappalettere C (2014) Remarks on residual stress measurement by hole-drilling and electronic speckle pattern interferometry. ScientificWorldJournal 2014: $1-7$

13. Lohe D, Vohringer O (2002) Handbook of residual stress and deformation of steel, vol. I

14. V. P. Group (2010) Measurement of residual stresses by the holedrilling* strain gage method, Tech Note TN-503 11053:19-33

15. Stefanescu D, Truman CE, Smith DJ, Whitehead PS (2006) Improvements in residual stress measurement by the incremental centre hole drilling technique. Exp Mech 46(4):417-427

16. Effertz PS, Fuchs F, Enzinger N (2017) Modelling the flash formation of linear friction welded $30 \mathrm{CrNiMo} 8$ high strength steel chains. Int J Adv Manuf Technol 92:2479-2486

17. Loffelmann J (2012) Systematische Untersuchung der Schweissparameter beim linearen Reibschweissen.pdf, 2nd IIW European-South American School of Welding and Correlated Processes

18. Nobre JP, Kornmeier M, Dias AM, Scholtes B. Use of the holedrilling method for measuring residual stresses in highly stressed shot-peened surfaces, vol. XL, p. 289-297

19. Buchanan DJ, John R (2014) A residual stress redistribution in shot peened samples subject to mechanical loading. Mater Sci Eng A 615:70-78

20. Xie P, Zhao H, Liu Y, Xie P, Zhao H, Liu Y (2017) Measuring residual stresses in linear friction welded joints composed by dissimilar titanium measuring residual stresses in linear friction welded joints composed by dissimilar titanium, Science and technology of welding and joining vol. XXI, no.5

21. Turner R, Ward RM, March R, Reed RC (2012) The magnitude and origin of residual stress in Ti-6Al-4V linear friction welds: an investigation by validated numerical modeling. Metall Mater Trans B Process Metall Mater Process Sci 43(1):186-197

22. Frankel P, Preuss M, Steuwer A, Withers PJ, Bray S (2009) Comparison of residual stresses in Ti-6Al-4V and Ti-6Al-2Sn4Zr-2Mo linear friction welds. Mater Sci Technol 25(5):640-650 